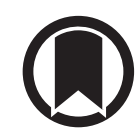

CrossMark

\title{
Adverse respiratory effects of opioids for chronic breathlessness: to what extent can we learn lessons from chronic pain?
}

\author{
From the authors:
}

We would like to thank K.T.S. Pattinson and colleagues for their interest in our review and their comprehensive comments [1]. We agree that the quality of the included studies was low, and the studies were small and not designed to examine the safety of opioids, as stated in our discussion [2]. Indeed, respiratory depression was not included as an outcome in over half of the studies. Of note, in the 25 studies that did include the outcome, only 11 stated a definition. Therefore, we recommended in our review to include "a common respiratory outcome set in all trials of opioids for breathlessness, so that a more robust synthesis could be conducted". Although chemoreflex response is useful in laboratory research, measurement of blood gases remains the basis for evaluation in clinical practice, with the assessment of arterial blood gases being more reliable than the assessment of capillary blood gases [3] or transcutaneous measurement [4].

K.T.S. Pattinson and colleagues suggest using knowledge from the world of analgesia for chronic noncancer pain. A systematic review published in 2015 [5] concluded that for some harms, including dependence, "higher opioid doses are associated with increased risk". Therefore, it is questionable whether this knowledge can be extrapolated to the treatment of chronic breathlessness. The risk of tolerance to opioids used for analgesia has indeed been shown in patients on methadone maintenance therapy, using methadone doses of $50 \mathrm{mg}$ (equivalent to $480 \mathrm{mg}$ morphine) per day or more [6, 7]. With analgesia, high doses and dose escalation titrating against severity of pain are usual practice, but patients with breathlessness are treated with low-dose opioids ( $\leqslant 30 \mathrm{mg}$ oral morphine equivalents a day [8]). Responders in a long-term effectiveness study (mean of 209.5 patient-days per participant) used a mean of $14 \mathrm{mg}$ per day, of which only $7.7 \%$ used the highest dose of $30 \mathrm{mg}$ per day to gain benefit [8]. In participants needing a dose increment up to $30 \mathrm{mg}$ per day to gain benefit, improvement continued without further dose titration over the following 7 days, a phenomenon not described in pain response [9].

At the population level, ЕкSтRÖм et al. [10] showed that dosages $<30 \mathrm{mg}$ oral morphine equivalents a day were not associated with increased risk of hospitalisation or death among patients with chronic obstructive pulmonary disease (COPD) using long-term oxygen therapy over a 4-year follow-up. The excess 30-day mortality seen in the large observational cohort study we discussed in our review was statistically significant but very small; other factors might explain these findings and it is likely that the overwhelming majority were prescribed opioids for pain and not breathlessness [11].

For the effect of opioid therapy on breathing during sleep, a dose-response relationship was shown with the apnoea-hypopnoea index, with the majority of patients receiving high-dose opioids $[12,13]$. It is not known if this conclusion can be drawn for low-dose opioids as well [14]. A recent overview of Cochrane reviews of opioid therapy for chronic pain found no case of respiratory depression, sleep apnoea or sleep-disordered breathing [15]. Nevertheless, while this Cochrane review did not focus on patients with COPD, we agree that measurement of overnight oximetry is needed to assess adverse effects of opioids for breathlessness and therefore we included pulse oximetry in the MORDYC study [16], for which we are currently collecting data.

Breathlessness is an extensive problem, experienced by many patients with chronic conditions [17, 18], and affects the quality of life of both patients and their caregivers [19]. Low-dose opioids are an effective

@ERSpublications

Chronic breathlessness: care must be taken not to generalise evidence on adverse effects of opioids from chronic pain inappropriately http://ow.ly/D7sR30kfskS

Cite this article as: Verberkt CA, van den Beuken-van Everdingen MHJ, Schols JMGA, et al. Adverse respiratory effects of opioids for chronic breathlessness: to what extent can we learn lessons from chronic pain?. Eur Respir J 2018; 52: 1800882 [https://doi.org/10.1183/13993003.00882-2018]. 
treatment for chronic breathlessness, without a reported increase in hospital admissions or mortality [8, 10, 20]. The American Thoracic Society statement on dyspnoea concludes that "clinically significant respiratory depression is uncommon with the doses used to treat dyspnea" [21]. This is confirmed by our review, in which only five out of 1064 patients who were examined for respiratory depression experienced an episode reported as respiratory depression. Only one of these cases required ventilator support and occurred in a patient treated with high-dose morphine [22]. However, since the effects of opioid treatment for chronic breathlessness have never been examined in a long-term and well-powered randomised controlled trial, the MORDYC study [16] and BEAMS study [23] are being conducted. The MORDYC study primarily focuses on the effect of slow-release morphine on respiratory outcomes. The results of both studies should give more insight in the long-term effects and the harms of opioid therapy in low doses.

We agree that lessons learnt in the field of chronic noncancer pain must be heeded but care must be taken not to generalise inappropriately. As PATTiNson [24] stated in a previous review regarding opioids as analgesia, "medical fear of respiratory depression means that pain is often undertreated and patients experience unnecessary suffering". A balanced and meticulous approach is needed to guide future research and clinical practice to ensure safe use of this effective intervention for chronic breathlessness.

Cornelia A. Verberkt $\oplus^{1}$, Marieke H.J. van den Beuken-van Everdingen ${ }^{2}$, Jos M.G.A. Schols ${ }^{1,3}$, Sushma Datla ${ }^{4}$, Carmen D. Dirksen ${ }^{5}$, Miriam J. Johnson ${ }^{4}$, Sander M.J. van Kuijk ${ }^{5}$, Emiel F.M. Wouters ${ }^{6,7}$ and Daisy J.A. Janssen ${ }^{2,6}$ ${ }^{1}$ Dept of Health Services Research, Maastricht University, Maastricht, the Netherlands. ${ }^{2}$ Centre of Expertise for Palliative Care, Maastricht University Medical Centre (MUMC+), Maastricht, the Netherlands. ${ }^{3}$ Dept of Family Medicine, Maastricht University, Maastricht, the Netherlands. ${ }^{4}$ Hull York Medical School, University of Hull, Hull, UK. ${ }^{5}$ Dept of Clinical Epidemiology and Medical Technology Assessment, MUMC+, Maastricht, the Netherlands. ${ }^{6}$ CIRO, Centre of Expertise for Chronic Organ Failure, Horn, the Netherlands. ${ }^{7}$ Dept of Respiratory Medicine, MUMC+, Maastricht, the Netherlands.

Correspondence: Cornelia A. Verberkt, Dept of Health Services Research, Maastricht University, PO Box 616, 6200 MD Maastricht, The Netherlands. E-mail: c.vandenberg@maastrichtuniversity.nl

Received: May 112018 | Accepted: May 202018

Support statement: The study to which this correspondence refers was supported by ZonMW grant 836031012 . Funding information for this article has been deposited with the Crossref Funder Registry.

Conflict of interest: C.A. Verberkt reports receiving grants from ZonMW, the Hague, during the conduct of the study. M.J. Johnson's institution has received payment from Mayne Pharma for clinical consultancy, during the conduct of the study. E.F.M. Wouters has received personal fees for board membership from Nycomed and Boehringer, grants from AstraZeneca and GSK, and payments for lectures from AstraZeneca, GSK, Novartis and Chiesi. D.J.A. Janssen reports receiving grants from ZonMw, the Hague, during the conduct of the study; lecture fees from Boehringer Ingelheim, GSK, AstraZeneca, Almirall and Chiesi, and a consultancy fee from MaynePharma, outside the submitted work. M.H.J. van den Beuken-van Everdingen reports grants from ZonMw, during the conduct of the study.

\section{References}

1 Pattinson KTS, Rowland MJ, Nickol AH, et al. Adverse respiratory effects of opioids for chronic breathlessness: learning lessons from chronic pain. Eur Respir J 2018; 51: 1702531.

2 Verberkt CA, van den Beuken-van Everdingen MHJ, Schols J, et al. Respiratory adverse effects of opioids for breathlessness: a systematic review and meta-analysis. Eur Respir J 2017; 50: 1701153.

3 Higgins C. Capillary blood gases: to arterialize or not. MLO Med Lab Obs 2008; 40: 44-47.

4 Pauwels RA, Buist AS, Calverley PM, et al. Global strategy for the diagnosis, management, and prevention of chronic obstructive pulmonary disease. NHLBI/WHO Global Initiative for Chronic Obstructive Lung Disease (GOLD) Workshop summary. Am J Respir Crit Care Med 2001; 163: 1256-1276.

5 Chou R, Turner JA, Devine EB, et al. The effectiveness and risks of long-term opioid therapy for chronic pain: a systematic review for a National Institutes of Health Pathways to Prevention Workshop. Ann Intern Med 2015; 162: 276-286.

6 Teichtahl $\mathrm{H}$, Wang $\mathrm{D}$, Cunnington $\mathrm{D}$, et al. Ventilatory responses to hypoxia and hypercapnia in stable methadone maintenance treatment patients. Chest 2005; 128: 1339-1347.

7 Khoubnasabjafari M, Ansarin K, Jouyban-Gharamaleki V, et al. Methadone concentrations in exhaled breath condensate. Serum and urine of patients under maintenance treatment. Iran J Pharm Res 2017; 16: 1621-1630.

8 Currow DC, McDonald C, Oaten S, et al. Once-daily opioids for chronic dyspnea: a dose increment and pharmacovigilance study. J Pain Symptom Manage 2011; 42: 388-399.

9 Currow DC, Quinn S, Greene A, et al. The longitudinal pattern of response when morphine is used to treat chronic refractory dyspnea. J Palliat Med 2013; 16: 881-886.

10 Ekstrom MP, Bornefalk-Hermansson A, Abernethy AP, et al. Safety of benzodiazepines and opioids in very severe respiratory disease: national prospective study. BMJ 2014; 348: g445.

11 Vozoris NT, Wang X, Fischer HD, et al. Incident opioid drug use and adverse respiratory outcomes among older adults with COPD. Eur Respir J 2016; 48: 683-693.

12 Webster LR, Choi Y, Desai H, et al. Sleep-disordered breathing and chronic opioid therapy. Pain Med 2008; 9 : 425-432. 
13 Rose AR, Catcheside PG, McEvoy RD, et al. Sleep disordered breathing and chronic respiratory failure in patients with chronic pain on long term opioid therapy. J Clin Sleep Med 2014; 10: 847-852.

14 Chowdhuri S, Javaheri S. Sleep disordered breathing caused by chronic opioid use: diverse manifestations and their management. Sleep Med Clin 2017; 12: 573-586.

15 Els C, Jackson TD, Kunyk D, et al. Adverse events associated with medium- and long-term use of opioids for chronic non-cancer pain: an overview of Cochrane Reviews. Cochrane Database Syst Rev 2017; 10: CD012509.

16 Verberkt CA, van den Beuken-van Everdingen MH, Franssen FM, et al. A randomized controlled trial on the benefits and respiratory adverse effects of morphine for refractory dyspnea in patients with COPD: protocol of the MORDYC study. Contemp Clin Trials 2016; 47: 228-234.

17 Thomas S, Bausewein C, Higginson I, et al. Breathlessness in cancer patients - implications, management and challenges. Eur J Oncol Nurs 2011; 15: 459-469.

18 Janssen DJ, Spruit MA, Wouters EF, et al. Daily symptom burden in end-stage chronic organ failure: a systematic review. Palliat Med 2008; 22: 938-948.

19 Johnson MJ, Yorke J, Hansen-Flaschen J, et al. Towards an expert consensus to delineate a clinical syndrome of chronic breathlessness. Eur Respir J 2017; 49: 1602277.

20 Ekström M, Bajwah S, Bland JM, et al. One evidence base; three stories: do opioids relieve chronic breathlessness? Thorax 2018; 73: 88-90.

21 Parshall MB, Schwartzstein RM, Adams L, et al. An official American Thoracic Society statement: update on the mechanisms, assessment, and management of dyspnea. Am J Respir Crit Care Med 2012; 185: 435-452.

22 Lang E, Jedeikin R. Acute respiratory depression as a complication of nebulised morphine. Can J Anaesth 1997; 45: 60-62.

23 Currow D, Watts GJ, Johnson M, et al. A pragmatic, phase III, multisite, double-blind, placebo-controlled, parallel-arm, dose increment randomised trial of regular, low-dose extended-release morphine for chronic breathlessness: Breathlessness, Exertion And Morphine Sulfate (BEAMS) study protocol. BMJ Open 2017; 7: e018100.

24 Pattinson KT. Opioids and the control of respiration. Br J Anaesth 2008; 100: 747-758. 